\title{
Amyand's Hernia in Rohingya Population: A Malaysian Field Hospital Experience
}

\author{
Theeran Gill ${ }^{1}$, Wazir Azzam ${ }^{1}$, Tan CL Eugene ${ }^{2}$, AK Khasnizal ${ }^{3}$ \\ Departments of ${ }^{1}$ General Surgery and ${ }^{2}$ Internal Medicine, Malaysian Field Hospital, Bangladesh; ${ }^{3}$ Department of General Surgery, \\ Hospital Tawau, Sabah, Malaysia.
}

\section{Corresponding Author: \\ Dr. Wazir Azzam \\ Email:wazirazzam@yahoo.com}

This is an Open Access article distributed under the terms of the Creative Commons Attribution License (creativecommons.org/ licenses/by/3.0).

Received Accepted Published

January 3, 2019

March 8, 2019

March 15, 2019

\begin{abstract}
Background: Amyand's hernia is often difficult to diagnose as it can be confused with a strangulated or an incarcerated inguinal hernia upon presentation where an emergent surgical management is required. Case Report: We present the case of a right Amyand's hernia on a 65 year old Rohingyan gentleman that presented to our Malaysian Field Hospital with right irreducible inguinal swelling associated with groin pain. He was diagnosed with recurrent right incarcerated inguinal hernia and underwent operation thereafter. Intra-operatively, we identified the presence of chronic scarring and densely adherent segments of the cecum and terminal ileum with a tight external inguinal ring. The appendix appeared grossly normal within the hernial sac. The patient underwent adhesiolysis and the hernia was reduced intra-abdominally which proceeded with a Lichtenstein repair without appendectomy. Conclusion: The incidence of Amyand's hernia is very rare. Hence the attending surgeon must be vigilant on diagnosing such cases as the mode of operation solely depends on the grade of inflammation of the appendix.
\end{abstract}

Keywords: Appendix, Appendectomy, Ileum, Inguinal Hernia, Pain.

\section{Introduction}

The denotation of Amyand's hernia relates to a rare form of inguinal hernia which occurs when the vermiform appendix is included in the hernial sac. This condition is an eponymous disease named after Claudius Amyand (1660 - 1740), a French born surgeon who successfully performed the very first appendectomy in 1735 [1]. However, this type of hernia is found during hernia repair intraoperatively, thus making it a rare phenomenon [2]. The prevalence of Amyand's hernia accounts for between 0.4 and $1 \%$ of all inguinal hernias. The occurrence of acute appendicitis in an Amyand's hernia accounts for $0.1 \%$ of all cases of appendicitis $[3,4]$. There is a prevalence of $11 \%$ of Amyand's hernia in adult patients with Meckel's diverticulum worldwide [2]. The preponderance is however three times more common in the pediatric population with the prevalence of $1 \%$ and is seen more often in males compared to females respectively $[2,3]$. Currently, there is no documented data of Amyand's hernia in the Rohingya population. This is a case of a right sided incarcerated Amyand's hernia which was diagnosed intra-operatively at the Malaysian Field Hospital (MFH) Cox's Bazar, Bangladesh during the deployment of Operation Starlight 2 under the prerogative of the Malaysian Prime Minister's Office.

\section{Case Report}

This is a case of a 65 years old gentleman of the Rohingya ethnicity who presented with swelling of the right side of the inguinal region for a period of 10 years. The swelling was initially reducible and gradually increasing in size for the last two years. A week prior to his visit at the Malaysian Field Hospital, the swelling became irreducible and caused persistent groin pain. Additionally, he 
had mild to moderate pinching squelching pain over the scrotum associated with mild abdominal cramps but was able to pass feces and flatus. The patient had not experienced any loss of appetite. On further history, the patient underwent surgery for a right inguinal hernia repair seven years ago in Myanmar. Otherwise, he had no other co morbidities. His condition was precipitated by his nature of work as a labourer back in Myanmar.

On clinical examination, he was afebrile with the blood pressure of 130/86 $\mathrm{mm} \mathrm{Hg}$, pulse rate of 88 beats per minute, respiratory rate of 21 breaths per minute and temperature of $36.8^{\circ} \mathrm{C}$. The cardiovascular and respiratory examinations were unremarkable. The abdominal examination revealed non-tender flat abdomen with a normoactive bowel sounds on auscultation and tympanic during percussion. The swelling over the right inguinal region was $15 \times 20 \mathrm{~cm}$ with no skin changes or erythema but irreducible with mild tenderness [Fig.1]. Both testes were palpable and were located in the scrotum. We had initially diagnosed the patient with a recurrent right sided incarcerated inguinal hernia and the patient was subjected to further investigation.

The patient was investigated with complete blood count $(\mathrm{CBC})$, viral screening, blood grouping, electrocardiogram (ECG) and chest $\mathrm{x}$-ray (CXR). On $\mathrm{CBC}$, the blood parameters were as follows: white blood cell counts $5.46 \times 10^{9} / \mathrm{L}$, granulocytes $3.49 \times 10^{9} / \mathrm{L}$, hemoglobin $13.4 \mathrm{~g} / \mathrm{dL}$ and platelet $222 \times 10^{9} / \mathrm{L}$. Viral screening for HIV, HbsAg and hepatitis C were negative. The patient's blood group was O positive. ECG showed sinus rhythm and CXR was unremarkable. We were unable to perform an ultrasonography examination due to the limitation of resources at our Malaysian Field Hospital in Cox's Bazar.

Subsequently, he was scheduled for a right sided open hernia repair after being reviewed by the attending surgeon and anaesthesiologist at our field hospital. Upon induction of general

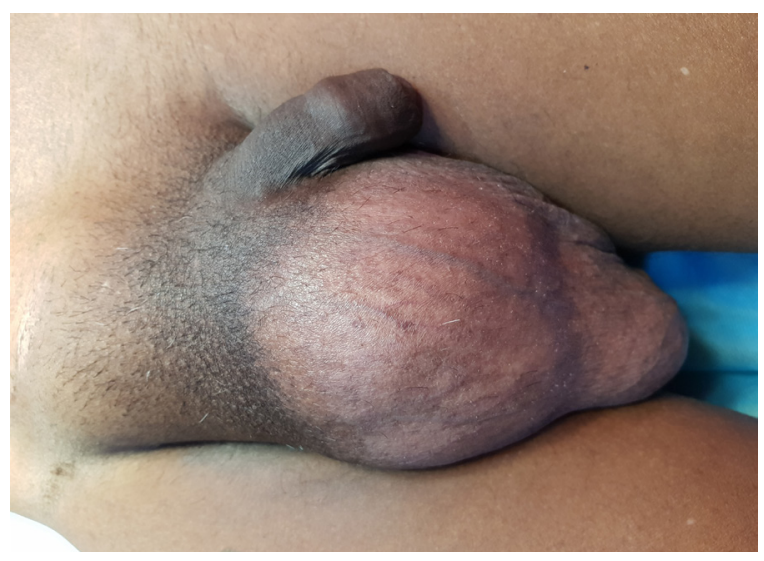

Fig.1: Recurrent right incarcerated inguinal hernia.

anaesthesia, prophylactic antibiotics were given with intravenous amoxicillin and clavulanate 1.2 grams. Incision was made in the skin crease of the right inguinal region, $2 \mathrm{~cm}$ above the superficial ring. The deep fascia was dichotomised and the external oblique aponeurosis identified and parted to reveal the underlying spermatic cord. The hernial sac was identified and isolated from the cord structures. Intra-operatively, we identified the presence of chronic scarring and densely adherent segments of the cecum and terminal ileum with a tight external inguinal ring presumably from the chronic incarceration within the right inguinal hernia. There were remnant sutures seen possibly from the previous operation. However, the appendix appeared grossly normal and not inflamed within the hernial sac [Fig.2]. The patient underwent adhesiolysis and the hernia was reduced intra-abdominally. The proximal sac was ligated and transfixed which then proceeded with a Lichtenstein tension free mesh repair without appendectomy. The post-operative course was uneventful and the patient was discharged well after three days. Patient follow-up at one week and one month did not reveal any recurrence.

\section{Discussion}

Amyand's hernia is a rare phenomenon characterized by the presence of the vermiform appendix, be it inflamed or not within the hernial 
sac. An incarcerated appendix within the hernial sac may be inflamed, infected and eventually lead to perforation or it may also present as being entirely healthy as it was seen in this case [5]. They are most commonly located on the right side due to the anatomical positioning of the appendix however on the left side, it is the result of a mobile cecum, situs inversus, malrotation or an excessively long appendix [6]. The present case, diagnosed intra-operatively, was the first ever case reported at our field hospital since its establishment in November 2017 to aid the Rohingya refugees. Amyand's hernia usually appears without signs of obstruction and in most cases ileus may be present unlike other inguinal hernias containing the bowel. Therefore, the differential diagnosis of Amyand's hernia include incarcerated or strangulated hernia, inguinal lymphadenitis, testicular torsion, acute epididymo-orchiditis, acute hydrocoele, Richter's hernia, testicular tumors and torsion of epididymal appendages $[3,7,8]$.

The incidence of Amyand's hernia is rare hence diagnosis pre-operatively remains ambiguous. Singal et al. [4] confirmed acute appendicitis in inguinal hernia pre-operatively on ultrasonography (USG) and recommended that USG is a very helpful investigation at a cheaper cost. Usually such diagnosis is made by demonstration of blind-ending tubular structure with thickened walls, in connection to the cecum within the hernia sac [9]. Luchs et al. [10] were the first to describe two cases of type 2 hernias on computer tomography (CT) scans. The clinical presentation in both cases was that of an incarcerated hernia. The presence of an inguinal hernia is usually obvious on CT scans, particularly in males and to confirm the presence of an Amyand's hernia, the sagittal and coronal reformats are particularly useful in identifying the blind-ending tubular appendix arising from the cecum and entering the inguinal canal. The size of the appendix is unreliable as collapsed small bowel loops can be similar in calibre [11].

Having said that, in the present case we were

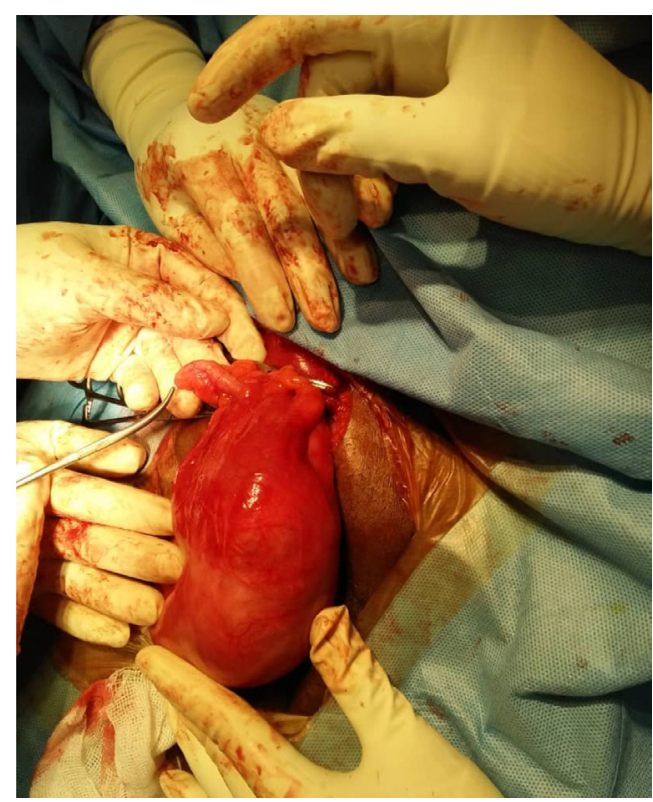

Fig.2: Densely adherent caecum and terminal ileum with grossly normal appendix within the hernial sac.

unable to proceed with instrumental diagnostic modalities due to constrains of being in a field hospital therefore, the diagnosis was made intraoperatively. The surgical approach and type of repair solely depends on the inflammatory status of the appendix. While some agree for appendectomy only if the appendix happens to be inflamed but others would agree with the former even otherwise to avoid any post-operative complications [4,1214]. As in the present case, whereby the normal vermiform appendix was found in the hernial sac, a prophylactic appendectomy was not performed in view of the possible contamination the procedure has which may lead to increased morbidity and recurrence. Losanoff and Basson [15,16] have distinguished four basic types of Amyand's hernias, which should be treated differently [Table 1].

A revised adaptation of this classification was introduced by Singal and Gupta [11] in which the appendix was included in the incisional hernial sac where a previous abdominal incision was made [17]. This phenomenon leads to the establishment of another subtype, type 5 which was then further 
divided into 3 categories respectively. Subtype 5 (a) was described as a normal appendix within an incisional hernia which should be managed as per type 1 . Subtype 5 (b) was described as a case of acute appendicitis within an incisional hernia with no abdominal sepsis and it is to be managed with appendectomy through hernia and primary endogenous repair of hernia, without mesh as per type 2. Lastly, subtype 5 (c) is a case of acute appendicitis within the incisional hernia, abdominal wall or peritoneal sepsis should be managed according to type 4 .

According to the classification above, the present case had a type 1 Amyand's hernia in which the appendix appeared grossly normal however the cecum and terminal ileum were densely adherent therefore he was subjected to hernia reduction and Lichtenstein tension free mesh repair without appendectomy respectively.

\section{Conclusion}

It has always been a surgeons dilemma in being vigilant on such rare occurrence of intra-operative findings such as Amyand's hernia given the limited resources especially in a field hospital. However, this type of hernia may lead to serious and lifethreatening complications if left untreated. Preoperative diagnosis is subjective as these kinds of hernias are diagnosed intra-operatively in most cases. The decision as to whether one should perform a simultaneous appendectomy and hernia repair is multi-factorial and solely depends on the type of hernia with its clinical presentation as per the Losanoff and Basson's criteria.

Contributors: TG: participated in the patients care, research design, performance of the research, and writing of the paper. WA and KAK participated in the patients care, performance of the research and writing of the paper. WA and TCL participated in revising the manuscript critically. TG will act as guarantor. All authors approved the final version of this manuscript.

Funding: None; Competing interests: None stated.
Table 1: Classification of Amyand's hernias after Losanoff and Basson [16].

\begin{tabular}{|l|l|l|}
\hline Classification & Description & Surgical Management \\
\hline Type 1 & $\begin{array}{l}\text { Normal appendix } \\
\text { within an inguinal } \\
\text { hernia. }\end{array}$ & $\begin{array}{l}\text { Hernia reduction, mesh } \\
\text { repair, appendectomy in } \\
\text { young patients. }\end{array}$ \\
\hline Type 2 & $\begin{array}{l}\text { Acute appendicitis } \\
\text { within an inguinal } \\
\text { hernia, no abdominal } \\
\text { sepsis. }\end{array}$ & $\begin{array}{l}\text { Appendectomy through } \\
\text { hernia, primary } \\
\text { endogenous repair of } \\
\text { hernia, no mesh. }\end{array}$ \\
\hline Type 3 & $\begin{array}{l}\text { Acute appendicitis } \\
\text { within an inguinal } \\
\text { hernia, abdominal } \\
\text { wall or peritoneal } \\
\text { sepsis. }\end{array}$ & $\begin{array}{l}\text { Laparotomy, } \\
\text { appendectomy, primary } \\
\text { repair of hernia, no } \\
\text { mesh. }\end{array}$ \\
\hline Type 4 & $\begin{array}{l}\text { Acute appendicitis } \\
\text { within an inguinal } \\
\text { hernia, related or } \\
\text { unrelated abdominal } \\
\text { pathology. }\end{array}$ & $\begin{array}{l}\text { Manage as types 1 to } \\
\text { treat second pathology } \\
\text { as appropriate. }\end{array}$ \\
\hline
\end{tabular}

\section{References}

1. Amyand C. Of an inguinal rupture, with a pin in the appendix caeci, incrusted with stone, and some observations on the wounds in the guts. Phil Trans R Soc Lond. 1736;39:329-342

2. Tsang WK, Lee KL, Tam KF, Lee SF. Acute appendicitis complicating Amyand's hernia: imaging features and literature review. Hong Kong Med J. 2014;20:255-257.

3. Michalinos A, Moris D, Vernadakis S. Amyand's hernia: a review. Am J Surg. 2014;207:989-995.

4. Singal R, Mittal A, Gupta A, Gupta S, Sahu P, Sekhon MS. An incarcerated appendix: report of three cases and a review of the literature. Hernia. 2012;16:91-97.

5. House MG, Goldin SB, Chen H. Perforated Amyand's hernia. South Med J. 2001;94:496-498.

6. Bakhshi GD, Bhandarwar AH, Govila AA. Acute appendicitis in left scrotum. Indian Journal of Gastroenterology. 2004;23:195.

7. D'Alia C, Lo Schiavo MG, Tonante A, Taranto F, Gagliano E, Bonanno L, et al. Amyand's hernia: case report and review of the literature. Hernia. 2003;7:50-51.

8. Bhide SS. Amyand's hernia. Indian J Pediatr. 2009;76:854-855.

9. Singal R, Gupta S. Amyand's hernia - pathophysiology, role of investigations and treatment. Maedica. 2011;6:321-327.

10. Luchs JS, Halpern D, Katz DS. Amyand's hernia: prospective CT diagnosis. Computer Assisted Tomography. 2000;24:884-886.

11. Constantine, Sarah. Computed Tomography Appearances of Amyand Hernia. Journal of Computer Assisted Tomography. 2009;33:359-362. 
12. Cankorkmaz L, Ozer H, Guney C, Atalar MH, Arslan MS, Koyluoglu G. Amyand's hernia in the children: a single center experience. Surgery. 2010;147:140-143.

13. Burgess PL, Brockmeyer JR, Johnson EK. Amyand hernia repaired with Bio-A: a case report and review. J Surg Educ. 2011;68:62-66.

14. Upadhyaya VD, Kumar V, Srivastava P, Gangopadhyaya AN. Amyand's hernia in infant: a rare entity. Kathmandu Univ Med J (KUMJ). 2009;7:143-144.
15. Losanoff JE, Basson MD. Amyand hernia: what lies beneath - a proposed classification scheme to determine management. Am Surg. 2007;73:1288-1290.

16. Losanoff JE, Basson MD. Amyand hernia: a classification to improve management. Hernia. 2008;12:325-326.

17. Bhatti SI, Hashmi MU, Tariq U, Haran Innocent Bhatti HI, Parkash J, Fatima Z. Amyand's Hernia: A Rare Surgical Pathology of the Appendix. Cureus. 2018;10:e2827. 